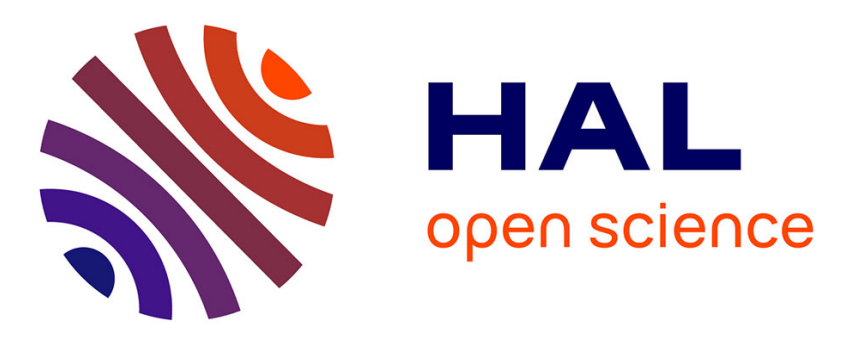

\title{
Nuclear changes in blood, early liver anomalies and hepatocellular cancers in flounder as prognostic indicator for a higher cancer risk?
}

Angela Köhler, Kathrin Ellesat

\section{- To cite this version:}

Angela Köhler, Kathrin Ellesat. Nuclear changes in blood, early liver anomalies and hepatocellular cancers in flounder as prognostic indicator for a higher cancer risk?. Marine Environmental Research, 2008, 66 (1), pp.149. 10.1016/j.marenvres.2008.02.071 . hal-00501963

\section{HAL Id: hal-00501963 \\ https://hal.science/hal-00501963}

Submitted on 13 Jul 2010

HAL is a multi-disciplinary open access archive for the deposit and dissemination of scientific research documents, whether they are published or not. The documents may come from teaching and research institutions in France or abroad, or from public or private research centers.
L'archive ouverte pluridisciplinaire HAL, est destinée au dépôt et à la diffusion de documents scientifiques de niveau recherche, publiés ou non, émanant des établissements d'enseignement et de recherche français ou étrangers, des laboratoires publics ou privés. 


\section{Accepted Manuscript}

Nuclear changes in blood, early liver anomalies and hepatocellular cancers in flounder (Platichthys flesus L.) as prognostic indicator for a higher cancer risk?

Angela Köhler, Kathrin Ellesat

PII: S0141-1136(08)00066-4

DOI: 10.1016/j.marenvres.2008.02.071

Reference: MERE 3218

To appear in: Marine Environmental Research

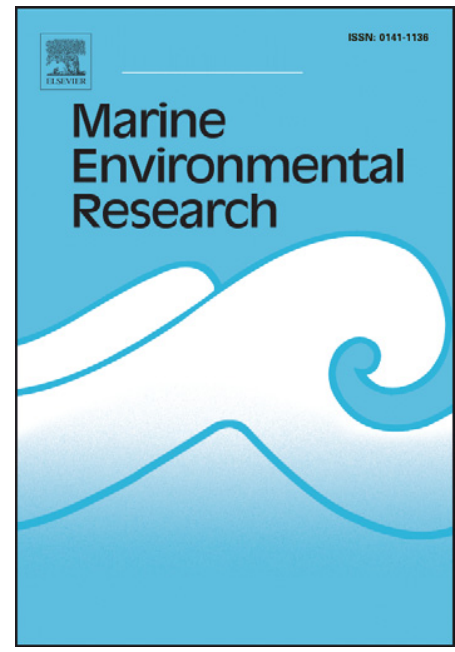

Please cite this article as: Köhler, A., Ellesat, K., Nuclear changes in blood, early liver anomalies and hepatocellular cancers in flounder (Platichthys flesus L.) as prognostic indicator for a higher cancer risk?, Marine Environmental Research (2008), doi: 10.1016/j.marenvres.2008.02.071

This is a PDF file of an unedited manuscript that has been accepted for publication. As a service to our customers we are providing this early version of the manuscript. The manuscript will undergo copyediting, typesetting, and review of the resulting proof before it is published in its final form. Please note that during the production process errors may be discovered which could affect the content, and all legal disclaimers that apply to the journal pertain. 


\title{
Nuclear changes in blood, early liver anomalies and \\ hepatocellular cancers in flounder (Platichthys flesus $L_{\text {. }}$ ) as \\ prognostic indicator for a higher cancer risk?
}

\begin{abstract}
Angela Köhler, Kathrin Ellesat
Department of Biosciences, Alfred Wegener Institute for Polar and Marine Research, Germany
\end{abstract}

\begin{abstract}
Nuclear changes (micronuclei) in blood are a well-established biomarker of toxic injury and related genotoxicity in mussel, fish and humans, as well. Yet, the relationship between the frequencies of micronuclei in blood and nuclear changes in liver cells itself and the higher potential risk to develop liver cancer is not yet fully implemented. We analysed and diagnosed macroscopic liver changes and H\&E and Feulgen stained histological liver sections (2 $\mu \mathrm{m}$ of thickness) together with blood smears (stained with Sytox Green) from same individuals in flounder caught along a well-known contaminant gradient in the North Sea. Results showed an increase in micronuclei frequencies in blood at the more contaminated sites and higher frequencies of macroscopically visible neoplastic liver changes. In livers of the same individuals, nuclear changes were diagnosed in early to degenerative liver lesion, extra-focal tissue surrounding neoplastic lesion and various stages during cancer progression from early neoplastic foci, benign adenomas and malignant carcinomas. The aim of this
\end{abstract}


approach is to expand diagnostic criteria, well-established in the frame of BEQUALM to nuclear changes which might help diagnosis of malignancies in doubtful cases.

Keywords: micronuclei in blood smears, liver neoplasms, nuclear changes in liver cancer, genotoxicity.

Corresponding author: Email address: Angela.Koehler@awi.de (A.Koehler)

The micronucleus test is a useful tool for biomonitoring effects of mutagenic/genotoxic environmental contaminants in humans and wildlife (Bolognesi et al., 2004; 2006; Barsiene et al., 2006; Barsiene et al., 2006). Exposure to these chemicals may give rise to chromosome fragments without spindle attachment or whole chromosomes that are unable to travel to the spindle poles during mitosis. These unattached chromosomes or fragments will not be incorporated into the daughter cell nuclei, thus, one or both daughter cells suffer from genetic loss. During telophase, a nuclear envelope is formed around these lagging parts of the DNA. After uncoiling of chromatin, they appear as small interphase nuclei besides the main nucleus, the micronuclei.

In the present study, the micronucleus test was applied in peripheral blood erythrocytes of European flounder (Platichthys flesus) (Chung et al., 2002; Parry and Parray, 2006). Frequency of micronuclei was determined at the differently contaminated stations to detect possible genotoxic effects in the study area. In addition, the occurrence of macroscopically visible liver neoplasms and progressive stages of liver cancers as diagnosed by histopathology were analysed in relation to micronuclei frequency in identical flounder individuals. Aim of this study was to elucidate whether the frequencies of micronuclei detected by non-destructive blood sampling could serve as a predictive marker of a higher risk 
of liver disease and cancer. On top, we wanted to know whether grades of hepatocellular cancers from pre-neoplastic foci, benign to malignant tumors are reflected by micronuclei presence in flounder blood and nuclear anomalies inside of the livers lesions.

Micronucleus frequencies were analysed in erythrocytes of whole blood smears of flounder stained with the dye Sytox Green, a nucleic acid binding dye, that obtains a $>500$ fold fluorescence enhancement when binding to DNA (excitation: $504 \mathrm{~nm}$, emission: $523 \mathrm{~nm}$ ) at an optimized concentration of $50 \mathrm{nM}$. Nuclei and micronuclei were scored with a fluorescence microscope (Axioskop, Zeiss, Germany). 2000 erythrocyte nuclei were counted per slide and micronucleus frequencies were established. Photographs of cells and micronuclei were taken with a digital colour camera (AxioCam MRc, Zeiss, Germany).

Diagnostic criteria for micronuclei identification were used for micronucleus scoring according to several authors (Al-Sabti and Metcalfe, 1995, Fenech, 2000, Fenech et al., 2003):

- The diameter of fish micronuclei varies between $1 / 10^{\text {th }}$ and $1 / 30^{\text {th }}$ of the mean diameter of the main nuclei

- Micronuclei are non-refractile and can therefore be readily distinguished from artefacts such as staining particles

- Micronuclei are not connected to the main nuclei

- Micronuclei may touch but not overlap the main nuclei and the micronuclear boundary should be distinguishable from the nuclear boundary

- Micronuclei usually have the same staining intensity as the main nuclei but occasionally staining may be more or less intense (Fig. 1A)

Comparing flounder with and without macroscopically visible liver nodules (tumours) caught at the polluted stations indicated significantly higher frequencies of micronuclei in the blood of those flounder bearing tumours (Fig 1B). Micronuclei formations increased with age/length of flounder ( $\mathrm{p}<0.02$, Mann-Whitney U-test) in accordance to increased tumour 
rates in older individuals. Frequencies of micronuclei in flounder blood smears clearly confirmed the known contamination situation in the German Bight influenced by the river Elbe (Fig.1C). Correspondingly, flounder caught close to the highly contaminated Elbe estuary showed higher micronuclei frequencies compare to the reference station in the north.

Interestingly, a clear increase of micronuclei in blood in flounder displaying malignant hepatocellular cancers ( $\mathrm{p}<0.02$, Kruskall Wallis, one-tailed analysis) diagnosed by histopathology using grading of cancers from preneoplastic, benign to malignant types (Koehler, 2004). Furthermore, alterations of nuclei were linked to the histological diagnosis of various types of liver lesions on the basis of Feulgen-stained liver sections, and a catalogue of potentially prognostic criteria of nuclear changes was developed. The observation of nuclear changes in hepatocytes delivered clear indications that phenomena such a karyomegaly and polyploidy are good indicators for increased genetic instability which is closely associated to tumour malignancy. Thus, nuclear changes in developing cancers might help to differentiate between benign and malignant cancer in doubtful cases and could be a useful addition to the diagnostic tools developed in the frame of international monitoring programmes.

On the basis of our findings, the frequency of micronuclei using blood smears as nondestructive method can be further developed into a highly valuable tool to screen larger geographic areas for the presence and effect of genotoxic chemicals.

\section{References}

Al-Sabti, K., and Metcalfe, C.D. (1995). Mutation Research, 343, 121-135.

Barsiene, J., Lehtonon, K.K., Koehler, A., Broeg, K., Vurinene, P.J., Lang, T., et al. (2006). Marine Pollution Bulletin, 53, 422-436.

Barsiene, J., Dedonyte, V., Rybakovas, A., Andreikenaite, L., and Andersen, O.K. (2006). Aquatic Toxicology, 78, 99-104. 
ACCEPTED MANUSCRIPT

Bolognesi, C., Perrone, E., Poggieri, P., Pampanin, D.M., and Sciutto, A. (2006). Aquatic Toxicology, 78, S93-S98.

Bolognesi, C., Landini, E., Perrone, E., and Roggieri, P. (2004). Mutation Research, 557, 109-117.

Chung, H.W., Kang, S.J., and Kim, S.Y. (2002). Mutation Research, 516, 49-56.

Fenech, M. (2000). Mutation Research, 455, 81-95.

Fenech, M., Chang, W.P., Kirsch-Volders, M., Holland, N., Bonassi, S., and Zeiger, E. (2003). Mutation Research, 534, 65-75.

Köhler, A. (2004). Aquatic Toxicology, 70, 257-276.

Parry, J.M., and Parry, E.M. (2006).Mutation Research, 607, 5-8. 


\section{Figure Caption}

Fig. 1: (A) Micronucleus in erythrocytes of blood smears stained with Sytox Green. (B) Number of micronuclei in flounder without and with macroscopic liver neoplasia, called tumour (box plots with medians and quartiles, N=15 each). (C) Frequency of micronuclei at the reference site Station 1 and 2 polluted Station 2 and 3 in the Elbe estuary $(\mathrm{N}=10$ per station). 


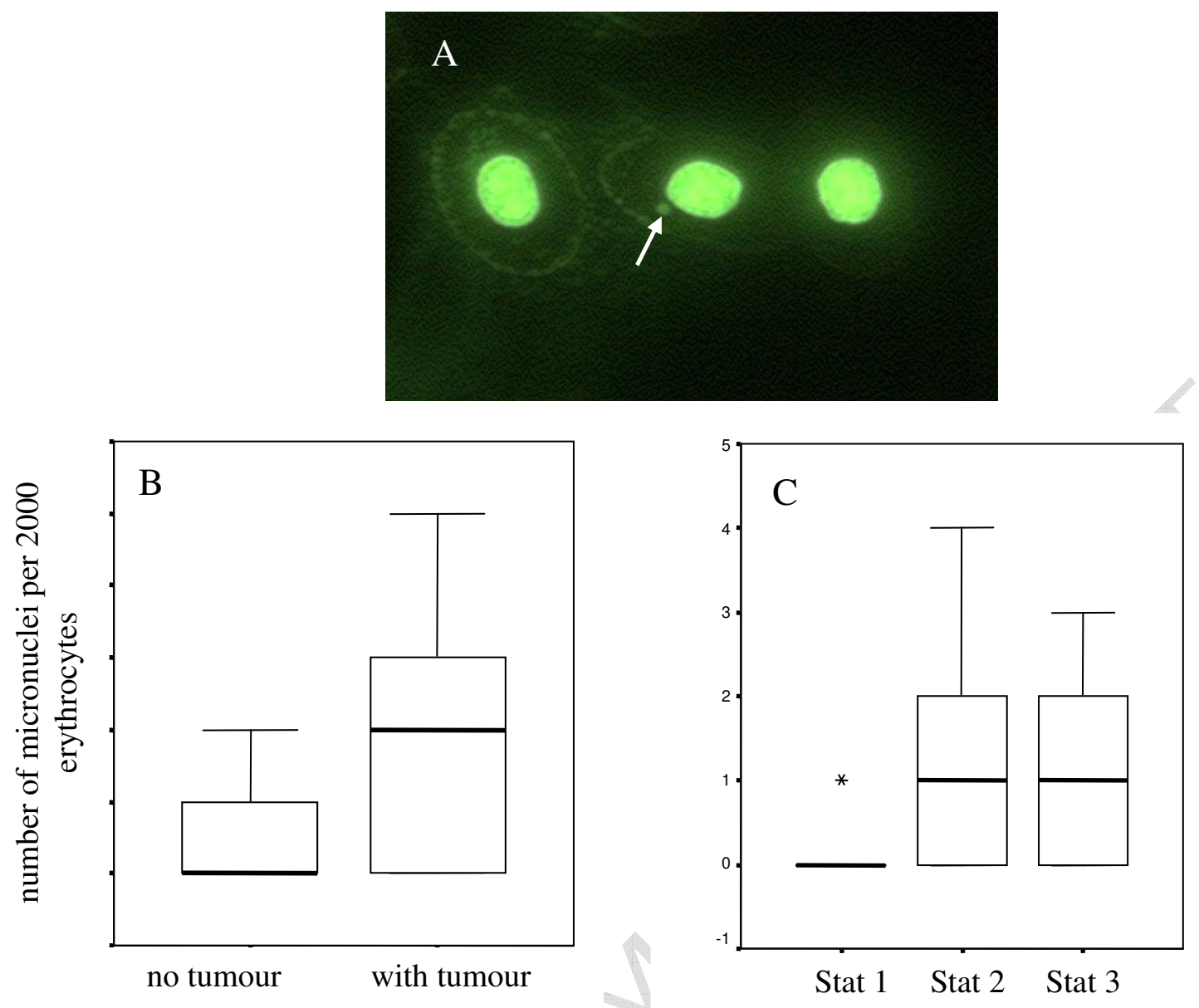

Figure 1 